\title{
PEMODELAN PEROLEHAN MASSA DAN WAKTU REAKSI PIROLISIS SERBUK GERGAJI KAYU JATI
}

\section{MODELING OF MASS YIELD AND REACTION TIME PYROLYSIS TEAK SAWDUST}

\author{
Novan Bayu Nugraha ${ }^{1}$, Yusfita Yusuf ${ }^{2}$, Gunawan Refiadi ${ }^{3}$ \\ 1,3 Jurusan Pendidikan Teknik Mesin STKIP Sebelas April Sumedang \\ ${ }^{2}$ Jurusan Pendidikan Matematika STKIP Sebelas April Sumedang \\ Jl.Angkrek Situ No.19, Sumedang, Telp. (0261) 202911 \\ Email:novan_bayu@yahoo.com
}

\begin{abstract}
ABSTRAK
Proses pirolisis menghasilkan arang, bio-oil dan gas. Untuk pemahaman proses pirolisis, maka mekanisme proses pirolisis didefinisikan dalam model matematika. Penelitan ini adalah kajian teoritik, untuk menentukan model matematika yang digunakan untuk memprediksi perolehan massa dan waktu yang optimum. Penelitian menggunakan persamaan perpindahan panas dan reaksi pirolisis. Variabel yang digunakan adalah temperatur (573, 598, 623, 648, 673 K), dengan sampel serbuk gergaji kayu jati kering. Model cukup baik untuk memprediksi proses pirolisis. Kondisi optimum didapatkan pada temperatur $598 \mathrm{~K}$, dengan waktu reaksi 3 jam 56 menit, produk yang didapatkan adalah $53,2 \%$ dari massa awal biomassa yang terdiri $29,99 \%$ arang dan $23,20 \%$ bio-oil.
\end{abstract}

Kata kunci : pirolisis, kajian teoritik, serbuk gergaji kayu jati, kondisi optimum

\section{ABSTRACT}

Pyrolysis process to produce charcoal, bio-oil and gas. For understanding the process of pyrolysis, the pyrolysis process mechanism defined in the mathematical model. This research is theoretical studies, to determine the mathematical models used to predict the optimum mass and time. Research using the model of heat transfer and pyrolysis reactions. The variables used were temperature (573, 598, 623, 648, 673 K), with samples of dried teak sawdust. Model good enough to predict the pyrolysis process. The optimum conditions obtained at a temperature of $598 \mathrm{~K}$, with a reaction time of 3 hours 56 minutes, the product obtained was $53.2 \%$ of the initial mass of biomass comprising $29.99 \%$ charcoal and $23.20 \%$ bio-oil.

Keywords: pyrolysis, theoretical study, teak sawdust, optimum conditions

\section{PENDAHULUAN}

Pemanfaatan biomassa sebagai sumber energi memiliki beberapa masalah terkait dengan sifat termofisik biomassa, yaitu nilai kalor yang rendah sekitar 17-19 MJ/kg, sifat biomassa yang higroskopis, dan sifat biomassa yang liat. Proses konversi termokimia merupakan proses yang tepat untuk meningkatkan sifat termofisik biomassa. Proses konversi termokimia yang telah dilakukan untuk memperbaiki sifat termofisik biomassa adalah proses pirolisis.

Proses pirolisis berlangsung dimulai pada temperatur $468 \mathrm{~K}$, mempertahankan 10-
$35 \%$ massa awal, dan memiliki nilai kalor 32 $\mathrm{MJ} / \mathrm{kg}$ (Tumuluru dkk., 2011). Proses pirolisis menghasilkan tiga jenis produk, yaitu produk padat atau arang, produk cair (bio-oil) (Mohan dkk. (2006), Qiang dkk. (2009)) yang berwarna kekuningan yang merupakan hasil kondensasi dari zat volatil yang terbawa aliran gas, dan produk gas yang tidak dapat terkondensasi. Faktor yang mempengaruhi proses pirolisis adalah suhu, ukuran partikel, dan kecepatan transfer panas.

Reaksi yang terjadi terjadi selama proses pirolisis dapat dijelaskan oleh mekanisme tiga reaksi paralel (TRP). Mekanisme reaksi TRP menggambarkan 
biomassa terdekomposisi melalui tiga jenis reaksi yang berlangsung berasamaan, yaitu menjadi arang, gas, dan bio-oil (Vincent dkk., 2010; Al-Haddad dkk., 2010). Gambar 1 menunjukkan mekanisme reaksi TRP yang terjadi. Model TRP memiliki tiga konstanta laju reaksi sesuai mekanisme yang terjadi, yaitu konstanta laju reaksi gas $\left(\mathrm{k}_{\mathrm{g}}\right)$, konstanta laju reaksi arang $\left(\mathrm{k}_{\mathrm{a}}\right)$, dan konstanta laju reaksi bio-oil $\left(\mathrm{k}_{\mathrm{l}}\right)$.

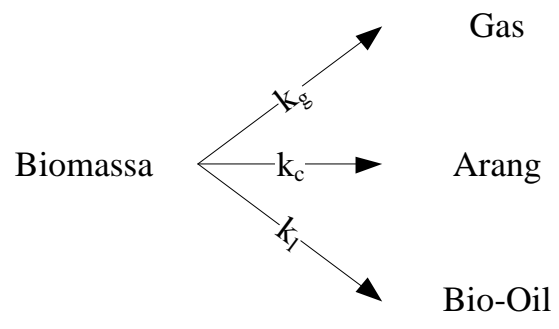

Gambar 1. Mekanisme reaksi pirolisis

Prediksi perolehan massa dan waktu reaksi yang optimum dari reaksi pirolisis dapat dilakukan dengan pemodelan matematika. Pendekatan pemodelan matematika yang akan digunakan pada kajian ini adalah model simulasi. Simulasi proses pirolisis menggunakan model matematika persamaan perpindahan panas bersamaan persamaan reaksi pirolisis, simulasi memerlukan data konstanta laju reaksi, sifat fisik, nilai awal dan nilai batas.

Simulasi yang dibandingkan hanya arang dan bio-oil, gas tidak dilakukan perbandingan disebabkan gas tidak diambil. Temperatur pirolisis yang digunakan adalah 573-673 ${ }^{\circ} \mathrm{C}$ menggunakan biomassa berupa serbuk gergaji kayu jati.

Data perolehan massa arang dan dan bio-oil pada proses pirolisis menggunakan data hasil penelitian Djauhari dkk. (2012) yang telah melakukan penelitian pirolisis menggunakan serbuk gergaji kayu jati, serbuk gergaji kayu jati sebelum dilakukan proses pirolises telah dikeringkan terlebih dahulu. Jenis reaktor yang digunakan pada penelitian adalah reaktor tubular unggun tetap dan dalam keadaan inert.

Asumsi yang digunakan untuk melakukan simulasi model matematika persamaan proses pirolisis yaitu menggunakan persamaan untuk partikel berbentuk bola, tidak terjadi perubahan geometri pada partikel selama proses pirolisis, panas yang terbawa aliran volatil jumlahnya kecil, panas reaksi yang terjadi bersifat endotermik dan nilainya kecil dibandingkan perpindahan panas koduktiv, dan energi aktivasi konstan.

\section{BAHAN DAN METODE}

Skema alat yang digunakan pada penelitian dapat dilihat pada Gambar 2. Serbuk gergaji kayu jati diletakkan dalam reaktor yang telah dipasang pengukur temperatur, kemudian reaksi pirolisis berlangsung dalam reaktor pada temperatur yang di tentukan.

Serbuk gergaji akan berubah menjadi arang, zat volatil yang terlepas dari serbuk gergaji akan didinginkan menggunakan pendingin dengan media air pendingin. Zat volatil yang ter-kondensasi akan menjadi biooil, sedangkan yang tidak terkondensasi terlepas menjadi gas.

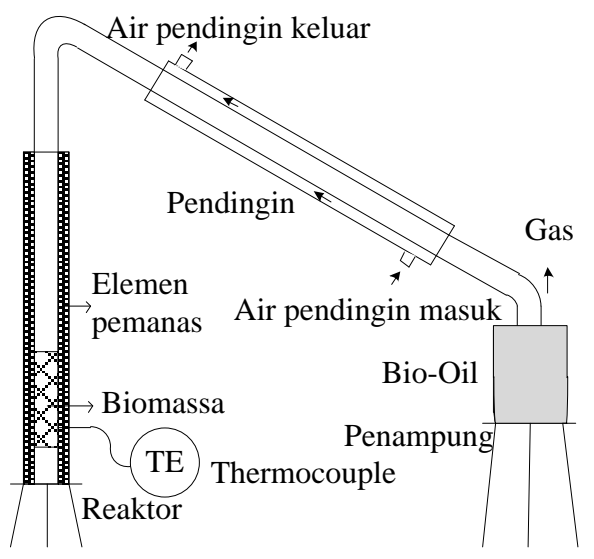

Gambar 2. Skema Alat

Pemodelan proses pirolisis serbuk gergaji kayu jati menggunakan persamaan perpindahan panas bersamaan dengan persamaan reaksi pirolisis. Untuk melakukan simulasi diperlukan data konstanta laju reaksi, sifat fisik, dan nilai awal dan nilai batas. Perolehan massa arang dan bio-oil didapatkan dari hasil simulasi.

Perolehan massa arang dan bio-oil hasil simulasi kemudian dilakukan perbandingan untuk melihat kesesuaian model yang dikembangkan. Untuk melihat kesesuaian model proses pirolisis dilakukan pembandingan dengan data hasil penelitian. Data perolehan massa arang dan massa bio-oil didapatkan dari penelitian yang dilakukan oleh Djauhari dkk. (2012). Biomassa yang digunakan adalah serbuk gergaji kayu jati 
sebanyak 100 gr yang telah dikeringkan. Variabel temperatur pirolisis yang digunakan adalah 573, 598, 623, 648, dan $673 \mathrm{~K}$.

Biomassa terdekomposisi menjadi arang, bio-oil, dan gas, memerlukan waktu agar seluruh biomassa selesai bereaksi. Waktu penyelesaian dari proses pirolisis selanjutnya dihitung menggunakan model proses pirolisis.

Simulasi lanjutan kemudian dilakukan untuk mengetahui kondisi perolehan massa arang dan bio-oil yang paling banyak pada waktu pemrosesan yang paling singkat.

\section{A. MODEL MATEMATIKA PROSES PIROLISIS}

Proses pirolisis terjadi diakibatkan perpindahan panas yang mengakibatkan peningkatan temperatur partikel biomassa, sehingga terjadi reaksi pirolisis. Perubahan akibat reaksi pirolisis yang berlangsung menghasilkan produk reaksi pirolisis yaitu arang, bio-oil dan gas. Skema model yang digunakan dapat dilihat di Gambar 3.

\section{PERPINDAHAN PANAS}

Persamaan 1 menunjukkan persamaan perpindahan panas dari lingkungan (reaktor), yang dikonsumsi oleh partikel padat, dan panas yang diserap oleh volatil dan uap air (Felfi, 2002; Park dkk, 2010). Persamaan perpindahan panas menggunakan partikel berbentuk bola dan tidak terjadi perubahan geometri selama proses pirolisis.

$$
\begin{aligned}
\frac{\partial}{\partial t}\left(C_{p i} \rho_{i}\right) T+\frac{\partial}{\partial r}\left(C_{p^{*}} \rho_{i^{*}} u\right) T= \\
\frac{1}{r^{2}} \frac{\partial T}{\partial r}\left(r^{2} \lambda \frac{\partial T}{\partial r}\right)+Q
\end{aligned}
$$

Al-Haddad dkk. mengungkapakan untuk panas yang terbawa oleh zat volatil ketika keluar dari partikel dapat diabaikan. Umpan masuk dalam keadaan kering, sehingga persamaan perpindahan panas yang digunakan adalah Persamaan 2.

$$
\frac{\partial}{\partial t}\left(C_{p i} \rho_{i}\right) T=\frac{1}{r^{2}} \frac{\partial T}{\partial r}\left(r^{2} \lambda \frac{\partial T}{\partial r}\right)+Q
$$

Panas reaksi yang terjadi bersifat endotermik dan nilainya kecil dibandingkan perpindahan panas koduktif, sehingga panas reaksi dapat diabaikan, sehingga persamaan 2 panas menjadi persamaan 3 .

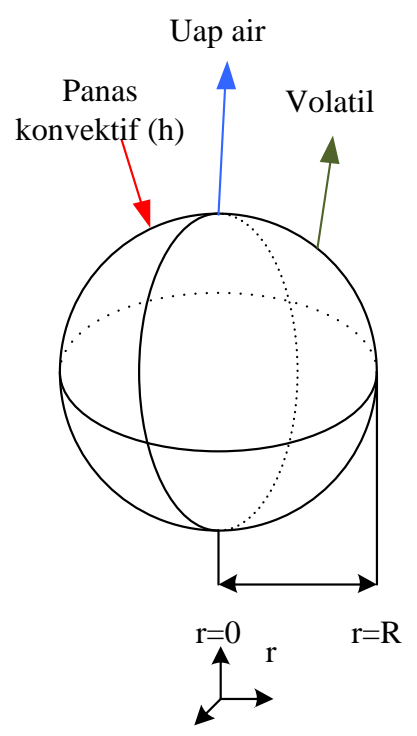

(a) partikel bola

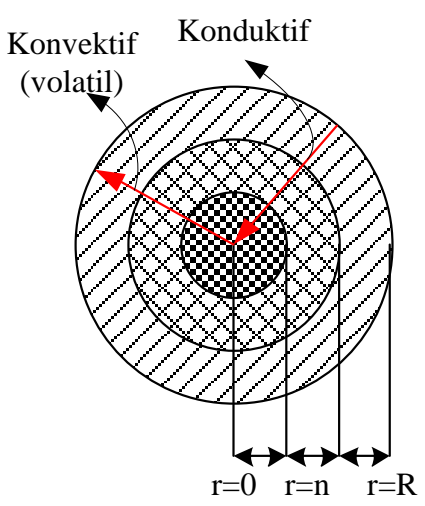

(b) perpindahan panas

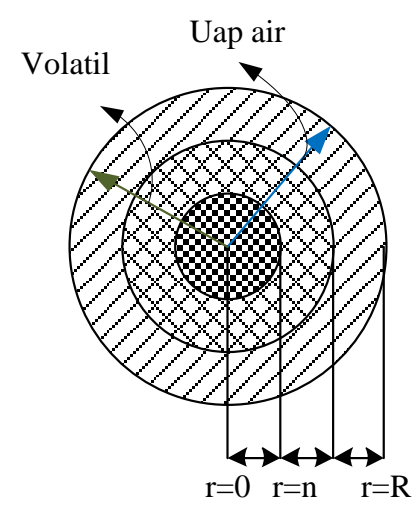

(c) perpindahan massa

Gambar 3. Model partikel bola 


$$
\frac{\partial}{\partial t}\left(\rho_{i} C_{p i} T\right)=\frac{1}{r^{2}} \frac{\partial T}{\partial r}\left(r^{2} \lambda \frac{\partial T}{\partial r}\right)
$$

Cp adalah kapasitas panas $\left(\mathrm{J} \cdot \mathrm{kg}^{-1} \cdot \mathrm{K}^{-1}\right)$, $\rho$ adalah densitas $\left(\mathrm{kg} \cdot \mathrm{m}^{-3}\right), \quad \mathrm{T}$ adalah temperatur $(\mathrm{K}), \mathrm{t}$ adalah waktu $(\mathrm{s}), \quad \lambda$ konduktifitas termal $\left(\mathrm{W} \cdot \mathrm{m}^{-1} \cdot \mathrm{K}^{-1}\right), \mathrm{Q}$ adalah panas $\left(\mathrm{W} . \mathrm{m}^{-3}\right)$, u adalah kecepatan $\left(\mathrm{m} . \mathrm{s}^{-1}\right)$, i adalah komponen fasa padat, $i^{*}$ adalah komponen fasa gas, dan $\mathrm{r}$ adalah jari-jari.

\section{REAKSI}

Persamaan untuk model mekanisme TRP dapat dilihat pada Persamaan 4, Persamaan 5, dan Persamaan 6. Persamaan 4 menunjukkan reaksi dekomposisi biomassa, persamaan 5 biomassa terkonversi menjadi arang, dan persamaan 6 menunjukkan biomassa terkonversi menjadi bio-oil (liquid).

$$
\begin{gathered}
\frac{\partial \rho_{b}}{\partial t}=-\left(k_{g}+k_{a}+k_{t}\right) \rho_{b} \\
\frac{\partial \rho_{a}}{\partial t}=k_{a} \rho_{b} \\
\frac{\partial \rho_{l}}{\partial t}=k_{l} \rho_{b}
\end{gathered}
$$

$\mathrm{k}_{\mathrm{g}}$ adalah konstanta laju reaksi untuk komponen gas $\left(\mathrm{s}^{-1}\right), \mathrm{k}_{\mathrm{a}}$ adalah konstanta laju reaksi untuk komponen arang $\left(\mathrm{s}^{-1}\right), \mathrm{k}_{1}$ adalah konstanta laju reaksi untuk komponen $\operatorname{tar}\left(\mathrm{s}^{-1}\right)$. $\rho_{\mathrm{b}}$ adalah densitas biomassa $\left(\mathrm{kg} . \mathrm{m}^{-3}\right), \rho_{\mathrm{a}}$ adalah densitas arang $\left(\mathrm{kg} . \mathrm{m}^{-3}\right), \rho_{\mathrm{l}}$ adalah densitas biooil $\left(\mathrm{kg} \cdot \mathrm{m}^{-3}\right)$.

\section{B. DATA SIMULASI PIROLISIS}

Penyelesaian simulasi model proses pirolisis menggunakan persamaan matematika perpindahan panas dan reaksi memerlukan data-data konstanta laju reaksi, sifat fisik, nilai awal dan nilai batas.

\section{KONSTANTA LAJU REAKSI}

Reaksi pirolisis memiliki nilai konstanta laju reaksi (k) mengikuti persamaan Arhennius (Persamaan 7), sehingga k sangat dipengaruhi oleh temperatur berlangsungnya reaksi. Pada temperatur yang tinggi reaksi berlangsung lebih cepat dibandingkan pada temperatur rendah.

$$
k=k_{0} \exp \left(-\frac{E a}{R_{\text {gas }} T}\right)
$$

$\mathrm{R}_{\text {gas }}$ adalah Konstanta gas universal $\left(\mathrm{J} . \mathrm{mol}^{-1} \cdot \mathrm{K}^{-1}\right), \quad \mathrm{k}_{0}$ adalah konstanta preeksponensial $\left(\mathrm{s}^{-1}\right)$, Ea adalah energi aktivasi $\left(\mathrm{J} . \mathrm{mol}^{-1}\right)$.

Nilai untuk konstanta laju reaksi dapat dilihat pada Tabel 1 (Al-Haddad dkk., 2010).

Tabel 1 Nilai konstanta laju reaksi TRP untuk kayu Oak

\begin{tabular}{|c|l|l|}
\hline $\begin{array}{c}\text { Konstanta laju } \\
\text { reaksi }\end{array}$ & $\mathrm{k}_{0}\left(\mathrm{~s}^{-1}\right)$ & $\begin{array}{l}\mathrm{Ea}\left(\mathrm{J} . \mathrm{mol}^{-}\right. \\
\left.{ }^{1}\right)\end{array}$ \\
\hline $\mathrm{k}_{\mathrm{g}}$ & $\begin{array}{l}1,43 \times \\
10^{4}\end{array}$ & $\begin{array}{l}8,86 \times \\
10^{4}\end{array}$ \\
\hline $\mathrm{k}_{\mathrm{a}}$ & $\begin{array}{l}4,12 \times \\
10^{6}\end{array}$ & $\begin{array}{l}1,13 \times \\
10^{5}\end{array}$ \\
& $\begin{array}{l}7,38 \times \\
10^{5}\end{array}$ & $\begin{array}{l}1,06 \times \\
10^{5}\end{array}$ \\
\hline $\mathrm{k}_{\mathrm{l}}$ & & \\
& \multicolumn{2}{|l}{} \\
\hline
\end{tabular}

\section{SIFAT FISIK}

Kapasitas panas dari kayu dan arang merupakan fungsi dari temperatur, untuk menghitung nilai kapasitas panas kayu dan arang berdasarkan fungsi temperatur menggunakan Persamaan 8 dan Persamaan 9.

$$
\mathrm{C}_{\mathrm{pb}}=1500+1,0 \mathrm{~T}
$$

$$
\mathrm{C}_{\mathrm{pa}}=420+2,09 \mathrm{~T}+6,85 \times 10^{-4} \mathrm{~T}^{2}
$$

$\mathrm{C}_{\mathrm{pb}}$ adalah kapasitas panas kayu ( $\mathrm{JKg}$ $\left.{ }^{1} \mathrm{~K}^{-1}\right), \mathrm{C}_{\mathrm{pa}}$ adalah kapasitas panas arang $\left(\mathrm{J} \mathrm{Kg}^{-}\right.$ $\left.{ }^{1} \mathrm{~K}^{-1}\right)$.

Nilai untuk koefisien perpindahan panas konduktif $(\lambda)$ dihitung berdasarkan derajat pirolisis (Al-Haddad dkk., 2010; Park dkk., 2010), untuk menghitung nilai $\lambda$ menggunakan Persamaan 10.

$$
\lambda=\theta \lambda_{b}+(1-\theta) \lambda_{a}
$$

Dimana $\theta$ adalah derajat pirolisis dihitung menggunakan Persamaan 11. $\lambda_{\mathrm{b}}$ 
adalah konduktifitas panas dari kayu dan $\lambda_{\mathrm{a}}$ adalah konduktifitas panas dari arang.

$$
\theta=1-\frac{\rho_{b}+\rho_{a}}{\rho_{0}}
$$

Nilai $\lambda_{\mathrm{b}}=0,160 \mathrm{Wm}^{-1} \mathrm{~K}^{-1}$ dan $\lambda_{\mathrm{a}}=0,007$ $\mathrm{Wm}^{-1} \mathrm{~K}^{-1}$. $\rho_{0}$ adalah densitas biomassa awal $\left(\mathrm{kgm}^{-3}\right)$.

\section{NILAI AWAL DAN NILAI BATAS}

Model proses pirolisis memerlukan nilai awal dan nilai batas untuk melakukan simulasi menggunakan model. Nilai awal dan nilai batas yang digunakan menggambarkan proses pirolisis yang terjadi. Nilai awal yang digunakan untuk menyelesaikan model proses pirolisis menggunakan Persamaan 12 sampai Persamaan 14.

$$
\begin{gathered}
\rho_{b}=\rho_{0} \\
\rho_{a}=\rho_{g}=0 \\
T=T_{0}
\end{gathered}
$$

$\rho_{\mathrm{g}}$ adalah densitas gas $\left(\mathrm{kg} \cdot \mathrm{m}^{-3}\right), \mathrm{T}_{0}$ adalah temperatur mula-mula (K)

Nilai batas yang digunakan untuk model proses pirolisis pada pusat partikel $(\mathrm{r}=0)$ tidak terjadi lagi perubahan temperatur, dan untuk dinding partikel $(r=R)$ mengalami pemanasan akibat perpindahan panas konvektif dari reaktor. Untuk menghitung nilai batas menggunakan Persamaan 15 dan Persamaan 16.

$$
\begin{gathered}
r=0 \rightarrow \frac{\partial T}{\partial r}=0 \\
r=R \rightarrow-\lambda \frac{\partial T}{\partial r}=h\left(T-T_{p y}\right)
\end{gathered}
$$

$\mathrm{T}_{\text {py }}$ adalah temperatur pirolisis $(\mathrm{K})$

Dimana $\mathrm{h}$ merupakan koefisien perpindahan panas konvektif $\left(\mathrm{W} \cdot \mathrm{m}^{-2} \cdot \mathrm{K}^{-1}\right)$, nilai dari $\mathrm{h}$ dihitung berdasarkan bentuk dari reaktor, reaktor yang digunakan adalah jenis reaktor tubular dengan diameter $10 \mathrm{~cm}$. Nilai $\mathrm{h}$ untuk reaktor yang digunakan adalah 14,7 $\mathrm{Wm}^{-2} \mathrm{~K}^{-1}$.

\section{HASIL DAN PEMBAHASAN}

Simulasi yang dilakukan menggunakan sampel serbuk gergaji kayu jati sebanyak 100 gram (Djauhari dkk., 2012). Serbuk gergaji kayu jati yang digunakan sudah dalam kering, dan reaktor yang digunakan adalah tubular reaktor unggun tetap dengan diameter $10 \mathrm{~cm}$. Produk yang dihasilkan berupa arang dan biooil ditimbang, kemudian produk yang ditimbang tersebut dibandingkan dengan bahan mula-mula, sehingga didapatkan perolehan produk.

Simulasi dilakukan dengan memasukkan variabel temperatur $(573,598$, 623, 648, $673 \mathrm{~K}$ ), kemudian hasil simulasi menggunakan persamaan perpindahan panas bersamaan persamaan reaksi TRP dibandingkan dengan data hasil penelitian.

\section{A. PERBANDINGAN DATA HASIL SIMULASI DAN DATA HASIL PENELITIAN}

Simulasi model pirolisis menggunakan persamaan perpindahan panas bersamaan persamaan reaksi TRP. Data yang digunakan adalah data hasil penelitan Djauhari dkk. (2012), biomassa yang digunakan adalah serbuk gergaji kayu jati kering dalam keadaan ruang.

Hasil simulasi kemudian dilakukan perbandingan dengan data hasil penelitian. Gambar 4 merupakan perbandingan antara hasil simulasi dan data hasil penelitian pada temperatur yang ditentukan .

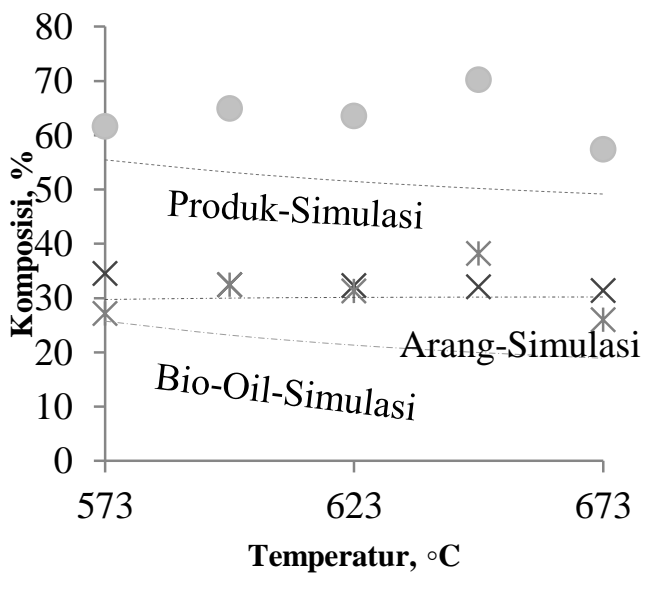

$\times$ Arang-Data $*$ Cair-Data $\odot$ Produk-Data

Gambar 4.Perbandingan data hasil simulasi dan data penelitian 
Simulasi yang dilakukan memiliki hasil yang cukup baik. Data hasil simulasi dan data hasil penelitan tidak persis sama namun pola yang dihasilkan antara data hasil simulasi dan data hasil penelitian memiliki pola yang sama pada pembentukan produk secara keseluruhan, dan produk padat (arang), namun memiliki perbedaan pada pembentukan produk bio-oil (Tabel 2) .

Tabel 2. Perbandingan data hasil penelitian dan simulasi

\begin{tabular}{|c|c|c|c|c|}
\hline $\mathrm{T}$ & \multicolumn{2}{|c|}{ Arang } & \multicolumn{2}{c|}{ Bio-Oil } \\
\hline $\mathrm{K}$ & $\begin{array}{c}\text { Data } \\
(\%)\end{array}$ & $\begin{array}{c}\text { Simulasi } \\
(\%)\end{array}$ & $\begin{array}{c}\text { Data } \\
(\%)\end{array}$ & $\begin{array}{c}\text { Simulasi } \\
(\%)\end{array}$ \\
\hline 573 & 34,48 & 29,71 & 27,11 & 25,79 \\
\hline 598 & 32,47 & 29,99 & 32,47 & 23,21 \\
\hline 623 & 32,28 & 30,13 & 31,27 & 21,35 \\
\hline 648 & 32,02 & 30,19 & 38,17 & 19,99 \\
\hline 673 & 31,36 & 30,21 & 26,00 & 18,93 \\
\hline
\end{tabular}

Tingkat kesalahan hasil simulasi dibandingkan data menggunakan kriteria perhitungan

$\left[(\text { data-simulasi)/data }]^{2} \times 100, \quad\right.$ tingkat kesalahan simulasi untuk arang paling tinggi adalah $1,91 \%$, sedangkan untuk bio-oil mencapai 22,69\% (Tabel 3).

Tabel 3. Tingkat kesalahan hasil simulasi dibandingkan data

\begin{tabular}{|c|c|c|}
\hline Temperatur & \multicolumn{2}{|c|}{ Galat } \\
\hline $\mathrm{K}$ & Arang (\%) & Bio-Oil (\%) \\
\hline 573 & 1,91 & 0,24 \\
\hline 598 & 0,58 & 8,13 \\
\hline 623 & 0,44 & 10,06 \\
\hline 648 & 0,33 & 22,69 \\
\hline 673 & 0,13 & 7,39 \\
\hline
\end{tabular}

Perbedaan antara data hasil simulasi dan data hasil simulasi disebabkan penggunaan data untuk kinetika reaksi pirolisis yang digunakan adalah data untuk kayu oak. Meskipun kayu oak dan kayu jati merupakan jenis kayu keras, namun terdapat perbedaan dari komposisi material kayu yang menimbulkan perbedaan hasil simulasi dan data penelitian.

Kayu jati memiliki komposisi penyusun lignoselulosa yaitu hemiselulosa
$14,4 \%$, selulosa $47,5 \%$, dan lignin $29,9 \%$ (Djauhari dkk., 2012). Kayu oak memiliki komposisi penyusun lignoselulosa yaitu hemiselulosa $35,0 \%$, selulosa 40,0 \%, dan lignin 25,0\% (Miller dan Bellan, 1997). Kayu oak memiliki komposisi hemiselulosa yang lebih tinggi dibandingkan kayu jati, komposisi selulosa hampir sama, dan lignin lebih sedikit. Hasil penelitan Yang dkk. (2007) reaksi pirolisis terhadap hemiselulosa berlangsung pada temperatur 493-588 K banyak menghasilkan gas $\mathrm{CO}$, selulosa pada temperatur 588-673 K mengasilkan gas $\mathrm{CO}_{2}$ yang lebih tinggi, dan lignin 423-1.173 K menghasilkan gas $\mathrm{H}_{2}$ dan $\mathrm{CH}_{4}$ reaksi dekomposisi lignin berlangsung lambat.

Komposisi hemiselulosa kayu oak yang lebih tinggi dibandingkan kayu jati menghasilkan gas $\mathrm{CO}$ yang lebih banyak untuk proses pirolisis pada temperatur 573$673 \mathrm{~K}$, gas CO merupakan gas yang tidak dapat terkondensasi pada kondisi ruang, sehingga produksi bio-oil kayu oak lebih rendah dibandingkan kayu jati.

\section{B. PEROLEHAN PRODUK DAN WAKTU PIROLISIS}

Massa produk pirolisis yang didapatkan dan waktu reaksi proses pirolisis tergantung pada temperatur proses pirolisis yang berlangsung. Simulasi lanjutan dilakukan untuk mengetahui gabungan perolehan produk arang dan bio-oil terbanyak (X) dan waktu reaksi (t) yang diperlukan untuk menyelesaikan proses pirolisis yang paling singkat.
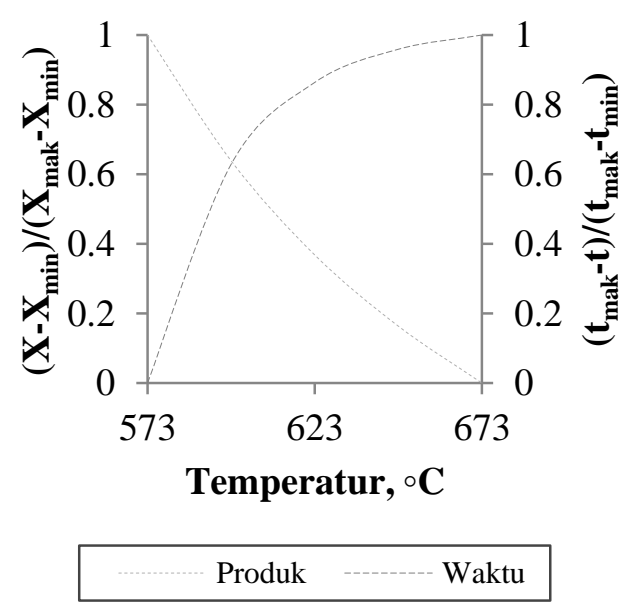

Gambar 5. Perbandingan hasil simulasi dan produk 
$\mathrm{X}$ maksimal $\left(\mathrm{X}_{\mathrm{mak}}\right)$ adalah $55,50 \%$ pada temperatur $573 \mathrm{~K}, \mathrm{X}$ minimal $\left(\mathrm{X}_{\min }\right)$ didapatkan pada temperatur $673 \mathrm{~K}$ sebesar 49,14\%. t maksimal ( $\mathrm{t}_{\mathrm{mak}}$ ) adalah 8 jam 57 menit didapatkan pada temperatur $573 \mathrm{~K}$ dan $\mathrm{t}$ minimal $\left(\mathrm{t}_{\mathrm{min}}\right)$ adalah 58 menit pada temperatur $673 \mathrm{~K}$

Simulasi yang dilakukan (Gambar 5) menunjukkan perolehan produk yang didapat dan waktu proses pirolisis yang paling baik didapatkan pada temperatur $598 \mathrm{~K}$ dan membutuhkan waktu untuk proses pirolisis selama 3 Jam dan 56 Menit. Kondisi tersebut produk yang didapatkan adalah 53,2\% dari massa awal biomassa yang terdiri 29,99\% Arang dan 23,20\% Bio-Oil. Sisa dari massa awal biomassa terlepas menjadi gas.

\section{KESIMPULAN}

Model matematika proses pirolisis memiliki hasil yang cukup baik untuk memprediksi perolehan massa arang dan biooil. Kondisi optimum untuk proses pirolisis berlangsung pada temperatur $598 \mathrm{~K}$ dengan waktu reaksi selama 3 Jam dan 56 Menit. Produk yang didapatkan adalah 53,2 \% dari massa biomassa yang terdiri 29,99\% Arang dan 23,20\% Bio-Oil.

\section{DAFTAR PUSTAKA}

1. Al-Haddad, M., Rendek, E., Corriou, J.P., dan Mauviel, G., 2010, "Biomass Fast Pyrolysis: Experimental Analysis and Modeling Approach", Energy \& Fuels, 24, 4689-4692.

2. Djauhari, A., Widiastuti, E., Yusuf, Y., Sovianti, W., 2012, "Bio-Oil Dari Pirolisis Serbuk Gergaji Kayu Jati (Tectona Grandis) Tanpa Gas $\mathrm{N}_{2}$ ”, Jurnal Fluida, 8, 19-24.
3. Felfi, F.F., Soler, P.B., dan Rocha, J.D., 2002, "Mathematical Modelling Of Wood And Briquettes Torrefaction”, Bioware, Campinas.

4. Miller, R.S., dan Bellan, J., 1997, “A Generalized Biomass Pyrolysis Model Based on Superimposed Cellulose, Hemicellulose and Lignin Kinetics", Combustion Science and Technology, 126, 97-137.

5. Mohan, D., Pittman Jr., C.U., Steele, P., 2006, "Pyrolysis of Wood/Biomass for Bio-Oil: A Critical Review", Energy \& Fuels, 20, 848-889.

6. Park, W.C., Atreya, A., dan Baum, H.R., 2010, "Experimental and Theoretical Investigation of Heat and Mass Transfer Processes During Wood Pyrolysis", Combustion and Flame, 157, 481-494.

7. Qiang, L., Wen-Zhi, L., Xi-Feng, Z., 2009, "Overview of Fuel Properties of Biomass Fast Pyrolysis Oils", Energy Conservation and Management, 50, 13761383.

8. Tumuluru, J.S., Sokhansanj, S., Wright, C.T., Boardman, R.D., dan Yancey, N.A., 2011, "A Review on Biomass Classification and Composition, CoFiring Issues and Pretreament Methods", 2011 ASABE Annual International Meeting, Kentucky.

9. Vincent, R., Alexandre, G., Mathieu, R., dan Rene, G., 2010, "Modelling Anhydrous Weight Loss of Wood Chips During Torrefaction in A Pilot Kiln", Biomass and Bioenergy, 34, 602-609.

10. Yang, H., Yan, R., Chen, H., Lee, D.H., dan Zheng, C., 2007, "Characteristics Of Hemicellulose, Cellulose And Lignin Pyrolysis", Fuel, 86, 1781-1788 